\title{
COMPORTAMIENTO DE HORMIGONES REFORZADOS CON Y SIN FIBRAS
}

\section{Marcelo Cadima Pino, Jorge Rosas Rodríguez y Francisco Aguirre Torrico}

\section{RESUMEN}

Se presenta el estudio de propiedades físicas y mecánicas de hormigones normales y reforzados con fibras sintéticas y de acero en mezclas de hormigón con resistencias de 21 y $28 \mathrm{~N} / \mathrm{mm}^{2}$, así como la influencia de las cuantías de fibras en la resistencia a la compresión y a la tracción; y el análisis estadístico de los resultados obtenidos. Los ensayos con métodos y procedimientos de la Norma ASTM, muestran que la cuantía de fibras más apta es la de 1,00 a $1,35 \mathrm{~kg} / \mathrm{m}^{3}$ y se observa un incremento en un $5 \%$ en el módulo de rotura. Por otro lado, se comprobó estadísticamente que el incremento en la resistencia a la compresión de hormigones reforzados con fibra no es significativa., por lo que la adición de fibras no afecta la resistencia a la compresión del hormigón. Comparando los espesores calculados, se puede afirmar que la introducción de una cuantía media de $1,0 \mathrm{~kg} / \mathrm{m}^{3}$ de fibras de plástico reduce el espesor de la losa en 15,0 mm, con respecto al hormigón sin fibras. Esta reducción del espesor disminuye el volumen de hormigón a ser utilizado. Por tanto, el costo total del hormigón con fibras es menor en un 2,2 \% para el hormigón de $21 \mathrm{~N} / \mathrm{mm}^{2}$ y 2,96 \% para el hormigón $28 \mathrm{~N} / \mathrm{mm}^{2}$.

Palabras Claves: Hormigón Reforzado con Fibras, Cuantías de Fibras, Asentamiento, Resistencia a la Compresión, Resistencia a la Tracción, Módulo de Elasticidad, Módulo de Rotura y Análisis Estadístico. 